\title{
STUDY ON A LOOP HEAT PIPE FOR A LONG-DISTANCE HEAT TRANSPORT UNDER ANTI-GRAVITY CONDITION
}

\author{
Kazuya Nakamura $^{{ }^{*}}$, Kimihide Odagiri ${ }^{1}$, Hosei Nagano $^{1}$ \\ ${ }^{1}$ Nagoya University, Furo-cho, Chikusa-ku, Nagoya-shi, Aichi 464-8603, Japan \\ *Corresponding Author: nakamura@ prop2.nuae.nagoya-u.ac.jp
}

\begin{abstract}
This paper reports the test results and evaluation of gravity effects on long-distance loop heat pipe (LLHP) with $10 \mathrm{~m}$ distances for heat transport. First, the LLHP was designed based on the one-dimensional steady-state model, fabricated and tested. Test results showed the LLHP could transport heat up to $340 \mathrm{~W}$ for $10 \mathrm{~m}$ and the thermal resistance between the evaporator and the condenser was $0.12 \mathrm{~K} / \mathrm{W}$ under horizontal condition. Next, the LLHP was tested in top-heat mode. The maximum heat transports were 310, 270, $220 \mathrm{~W}$ and the thermal resistances were $0.15,0.17,0.22 \mathrm{~K} / \mathrm{W}$ under $30,60,100 \mathrm{~cm}$ anti-gravity condition respectively. The heat transfer efficiency of the LLHP was discussed in detail. The evaluation results showed $71.4 \%$ of the $340 \mathrm{~W}$ heat load was dissipated at the condenser under the horizontal condition. On the other hand, 62.8, 61.8, 57.1\% of the maximum heat load was dissipated at the condenser under 30,60,100 cm anti-gravity condition respectively. The calculation model was in good agreement with the experimental results by considering the existence of a vapor pocket between the evaporator case and the vapor-liquid interface. This analysis indicated the vapor blanket generates easily and becomes thicker as anti-gravity effect increases.
\end{abstract}

KEYWORDS: Heat transfer, Long-distance loop heat pipe, PTFE porous wick, Two-phase flow

\section{Nomenclature}

\begin{tabular}{|c|c|c|c|c|c|}
\hline$A$ & surface area & $\left(\mathrm{m}^{2}\right)$ & $Q_{a m b}$ & heat loss from the evaporator & $(\mathrm{W})$ \\
\hline$A_{0}$ & heat dissipation area of no fin part & $\left(\mathrm{m}^{2}\right)$ & $Q_{e v}$ & heat of vaporization & $(\mathrm{W})$ \\
\hline$C R$ & $\begin{array}{l}\text { contact thermal resistance between } \\
\text { pipe and insulator }\end{array}$ & $(\mathrm{K} / \mathrm{W})$ & $Q_{g r}$ & superheat of groove & (W) \\
\hline$D$ & diameter & $(\mathrm{m})$ & $Q_{h l}, Q_{h l}^{\prime}$ & $\begin{array}{l}\text { heat leak from the evaporator to the } \\
\text { CC }\end{array}$ & $(\mathrm{W})$ \\
\hline$h$ & heat transfer coefficient & $\left(\mathrm{W} / \mathrm{m}^{2} \mathrm{~K}\right)$ & $Q_{\text {load }}$ & heat load & $(\mathrm{W})$ \\
\hline$h_{e v}$ & $\begin{array}{l}\text { heat transfer coefficient from the } \\
\text { evaporator to the vapor-liquid } \\
\text { interface of the wick }\end{array}$ & $\left(\mathrm{W} / \mathrm{m}^{2} \mathrm{~K}\right)$ & $Q l$ & heat loss & (W) \\
\hline$H D$ & $\begin{array}{l}\text { height difference between the } \\
\text { evaporator and the condenser }\end{array}$ & $(\mathrm{cm})$ & $r$ & radius & (m) \\
\hline$k$ & thermal conductivity & $(\mathrm{W} / \mathrm{mK})$ & $R$ & $\begin{array}{l}\text { thermal resistance from the } \\
\text { evaporator to the condenser }\end{array}$ & $(\mathrm{K} / \mathrm{W})$ \\
\hline$L$ & length & $(\mathrm{m})$ & $R_{\text {fin }}$ & $\begin{array}{l}\text { thermal resistance between the pipe and } \\
\text { the fin }\end{array}$ & $(\mathrm{K} / \mathrm{W})$ \\
\hline$\dot{m}$ & mass flow rate & $(\mathrm{kg} / \mathrm{s})$ & $S$ & cross-sectional area & $\left(\mathrm{m}^{2}\right)$ \\
\hline$P$ & pressure & $(\mathrm{Pa})$ & $T, T$ & temperature & $(\mathrm{K})$ \\
\hline \multicolumn{6}{|c|}{ Greek } \\
\hline$\lambda$ & latent heat & $(\mathrm{J} / \mathrm{kg})$ & $\sigma$ & surface tension & $(\mathrm{N} / \mathrm{m})$ \\
\hline$\varphi$ & porosity & $(-)$ & $\theta$ & contact angle & $\left({ }^{\circ}\right)$ \\
\hline$\rho$ & density & $\left(\mathrm{kg} / \mathrm{m}^{3}\right)$ & $\eta$ & fin efficiency & $(-)$ \\
\hline
\end{tabular}




\begin{tabular}{llll}
\multicolumn{2}{l}{ Abbreviations } \\
$a m b$ & ambient & $i n s$ & insulator \\
$a \_b$ & from a to b & $l l$ & liquid line \\
$c a$ & case & $l$ & l-th thermocouples \\
$c a p$ & capillary limit & $n u c$ & nucleate boiling \\
$c c$ & CC & $o$ & outer \\
$c o n$ & condenser & $s$ & solid \\
$e c$ & evaporator case & $s a t$ & saturation \\
$e f f$ & effective & $s u p$ & superheating \\
$e v$ & evaporator & $v$ & vapor \\
$f$ & fluid & $v l$ & vapor line \\
$g r$ & groove & $w i$ & wick \\
$i$ & inner & &
\end{tabular}

\section{INTRODUCTION}

Loop heat pipe (LHP) is an efficient two-phase heat transfer device that utilizes the evaporation and condensation of a working fluid, and uses the capillary force developed in a fine porous wick for circulation [1-3]. It has been developed and applied in the field of space engineering, however, it is being investigated for use in the terrestrial field [4]. This is because of the current demand for energy saving and the LHP's advantages such as no utility power requirement, capability of transferring heat over long distance and antigravity orientation. Electronics and computers are quite a promising sphere of LHP application [5,6]. In the future, LHP could be applied in the field of smart houses, automobiles, snow melting [7]. Applying LHP to these fields, transferring heat over long distance and anti-gravity direction could be required. Considering LHP can be utilized in the smart houses, LHP could be applied to use the heat gained from the sun during daylight for floor heating, water heating, and heat storage tank.

In author's previous study, a long-distance loop heat pipe (LLHP) that has one-way heat transport distance of $10 \mathrm{~m}$ had been designed and fabricated based on a one-dimensional steady-state flow system [7]. The experimental results showed the fabricated long-distance loop heat pipe could transport heat up to $160 \mathrm{~W}$ and the thermal resistance between the heat absorbing part and the heat radiating part was $0.13 \mathrm{~K} / \mathrm{W}$. However, the LHP performance was not enough, that is, for the practical utilization, higher heat transport and lower thermal resistance, and the operation under anti-gravity condition could be necessary, also, the heat transfer efficiency needs to be evaluated.

When it comes to previous studies of the gravity effect on LHP, Riehl [8] and Chuang [9] experimentally showed anti-gravity effect results in the increase of LHP's operating temperature. Ku [2] and Mo et al [10] theoretically explained the increase of operating temperature from the point of increase of pressure drop between the evaporator and the compensation chamber (CC) due to gravity. Furthermore, Chuang [9] reported anti-gravity effect was crucial at low heat loads, because at low heat load, gravity effect plays an important role in the total pressure drop compared with the frictional pressure drop. However, anti-gravity effect could have further effects on LHP's operation and as a results, operating temperature could be further increased. Tang et al [11] developed anti-gravity loop-shaped heat pipe (AGLSHP) that has a continuous graded pore-size wick in the evaporator and the liquid line. The AGLSHP was able to transport $100 \mathrm{~W}$ under $40 \mathrm{~cm}$ anti-gravity condition, however, it would be difficult to transport heat over long distance because of the high pressure drop of the wick in the liquid line.

This paper reports the development of the $10 \mathrm{~m}$-class long-distance loop heat pipe based on the onedimensional steady-state model. Tests were conducted under horizontal and 30,60, $100 \mathrm{~cm}$ anti-gravity conditions. Anti-gravity effect on the operating temperature and the heat transport efficiency was evaluated based on the temperature data of the test results and calculation model. Total pressure drop was evaluated from the computational results. 


\section{Numerical modeling of loop heat pipe}

One-dimensional steady-state numerical model was constructed to design and evaluate the LLHP performance. Fig. 1 shows the configuration of LHP. LHP consists of cylindrical evaporator, vapor/liquid line, condenser and CC. A cylindrical wick is enclosed in the evaporator and a core and grooves are machined in the wick.

In this model, some assumptions are made: (1) the wick is fully saturated with liquid. (2) There is an axisymmetric flow in all the parts of the LHP. (3) The temperature of the CC's case is equal to the working fluid in it. (4) Heat leak from the evaporator case to the vapor line is disregarded.

\subsection{Evaporator and wick model}

The energy balance in the evaporator can be expressed by eq. (1).

$$
Q_{\text {load }}=Q_{e v}+Q_{g r}+Q_{h l}+Q_{a m b}
$$

$Q_{e v}$ is written by eq. (2) and (3).

$$
\begin{gathered}
Q_{e v}=h_{e v} A_{e v}\left(T_{e c}-T_{e v}\right) \\
Q_{e v}=\dot{m} \lambda
\end{gathered}
$$

Where, $h_{e v}$ is estimated from the comparison of steady-state temperature between the experimental and the calculation results, as it substantially depends on the contact condition between the evaporator and the wick and the position of the vapor-liquid interface. $Q_{g r}$ is computed by the heat transfer coefficient of the forced convection of the vapor through the groove. $Q_{h l}$ consists of the heat leak through the wick $\left(Q_{e v_{-} w i}\right)$ and the evaporator case $\left(Q_{e c \_c a}\right)$ and is expressed by eq. (4).

$$
Q_{h l}=Q_{e v_{-} w i}+Q_{e c_{-} c a}
$$

$Q_{e \nu_{\_} w i}$ and $Q_{e c \_c a}$ are calculated by eq. (5) and (6) respectively.

$$
\begin{gathered}
Q_{e v_{-} w i}=\frac{2 \pi L_{w i} k_{e f f}}{\log \left(D_{o} / D_{i}\right)}\left(T_{e v}-T_{c c}\right) \\
Q_{e c_{-} c a}=k_{c a} S_{c a}\left(T_{e c}-T_{c c}\right)
\end{gathered}
$$

Where, $k_{\text {eff }}$ is calculated by eq. (7) with eq. (8) and (9).

$$
\begin{gathered}
k_{e f f}=\left(k_{\max }\right)^{0.42} \times\left(k_{\min }\right)^{0.58} \\
k_{\max }=\varphi k_{f}+(1-\varphi) k_{s} \\
k_{\min }=\frac{k_{f} k_{s}}{\varphi k_{f}+(1-\varphi) k_{s}}
\end{gathered}
$$

$Q_{a m b}$ is calculated by the heat transfer coefficient of the natural convection of the ambient air.

\subsection{Transport lines and condenser}

The calculations for the transport lines and the condenser are explained in Ref. [7].

\subsection{Compensation Chamber}

The CC temperature $\left(T_{c c}{ }^{\prime}\right)$ is determined by the pressure value at the $\mathrm{CC}$ and the vapor saturation curve of working fluid expressed by eq. (10).

$$
T_{c c}{ }^{\prime}=T_{s a t}\left(P_{c c}\right)
$$

The heat leak from the evaporator to the $\mathrm{CC}\left(Q_{h l}{ }^{\prime}\right)$ is calculated by eq. (4) balancing the amount of subcooling of the returning liquid $\left(Q_{c c_{-} l l}\right)$ and the heat loss from the $\mathrm{CC}$ to ambient air $\left(Q_{c c_{-} a m b}\right)$, and is expressed by eq. (11).

$$
Q_{h l}^{\prime}=Q_{c c_{-} l l}+Q_{c c_{-} a m b}
$$

\subsection{Solution algorithm}

The solution flowchart is shown in Fig. 2. Simulations are conducted using the numerical analysis software MATLAB. The groove, vapor/liquid lines and condenser are divided into 10, 200, 200, and 200 
nodes respectively and calculations are conducted on every node. The physical properties of working fluid are obtained from REFPROP version 9.1 [12]. Calculation was stopped when the total pressure loss reached the capillary limit that is written by eq. (12)

$$
P_{\text {cap }}=\frac{2 \sigma \cos \theta}{r_{\text {pore }}}
$$

Contact angle $\theta$ was measured using the sessile drop method, and the average pore radius was measured using mercury porosimetry [13]. Here, note the contact angle under the LHP operation needs to be verified further as it not only depends on the wettability but also the other elements such as the evaporation, flow rate and characteristics of the porous body.

\section{Experiment}

\subsection{Configuration of the constructed LLHP}

10m-class LLHP was designed and fabricated based on the computation model. Fig. 3 shows the overview figure of the LLHP. Table 1 details the dimensions. The LLHP is constructed as shown in Fig. 3. Additional $1000 \mathrm{cc}$ tank was attached to the $\mathrm{CC}$ to accommodate the fluid inventory. The wick was machined from a Polytetrafluoroethylene (PTFE) porous material with eight grooves and a core are machined in the wick. PTFE would be suitable for use in the terrestrial field because it is easier to machine and less expensive than metal wicks [13]. Also, in comparison with metal wicks, it is indicated that LHP with PTFE wick can reduce the heat leak from the evaporator to $\mathrm{CC}$ and allow lower operating temperature owing to low thermal conductivity of PTFE [14]. The cooling method of the condenser was natural convection. AL5052 aluminum plate $(250 \times 810 \times 15 \mathrm{~mm})$ was attached to the condenser line on one side. On the other side, the four vertical fins were attached to enhance the natural air cooling; each fin was $30 \mathrm{~mm}$ in height with a $10 \mathrm{~mm}$ pitch and each array contained 20 fins. Ethanol was selected as working fluid and the $1250 \mathrm{cc}$ was enclosed. The volume of working fluid is designed so as not to dry-out, that is, even if all parts without CC are filled with liquid, liquid is supplied to the wick, also, designed so as not to be filled with liquid in the CC.

Table 1 LLHP characteristics

\begin{tabular}{|c|c|c|c|c|c|}
\hline \multirow{2}{*}{$\begin{array}{c}\text { Evaporator } \\
\text { (SUS304) }\end{array}$} & O.D & $21 \mathrm{~mm}$ & \multirow{2}{*}{$\begin{array}{c}\text { CC } \\
\text { (SUS304) }\end{array}$} & O.D & $60 \mathrm{~mm}$ \\
\hline & Length & $140 \mathrm{~mm}$ & & Length & $70 \mathrm{~mm}$ \\
\hline \multirow{8}{*}{$\begin{array}{l}\text { Wick } \\
\text { (PTFE) }\end{array}$} & O.D & $19 \mathrm{~mm}$ & Additional CC & capacity & $1000 \mathrm{cc}$ \\
\hline & I.D & $13 \mathrm{~mm}$ & \multirow{3}{*}{$\begin{array}{l}\text { Vapor Line } \\
\text { (SUS304) }\end{array}$} & O.D & $10 \mathrm{~mm}$ \\
\hline & Length & $140 \mathrm{~mm}$ & & I.D & $8 \mathrm{~mm}$ \\
\hline & Pore radius & $1.2 \mu \mathrm{m}$ & & Length & $10 \mathrm{~m}$ \\
\hline & Porosity & $34 \%$ & \multirow{3}{*}{$\begin{array}{l}\text { Liquid Line } \\
\text { (SUS304) }\end{array}$} & O.D & $6.4 \mathrm{~mm}$ \\
\hline & Permeability & $2 \times 10^{-14} \mathrm{~m}^{2}$ & & I.D & $4.6 \mathrm{~mm}$ \\
\hline & Groove No. & 8 & & Length & $10 \mathrm{~m}$ \\
\hline & $\begin{array}{c}\text { Contact angle } \\
\text { with ethanol }\end{array}$ & $30^{\circ}$ & \multirow{3}{*}{$\begin{array}{l}\text { Condenser } \\
\text { (SUS304) }\end{array}$} & O.D & $10 \mathrm{~mm}$ \\
\hline \multirow{2}{*}{$\begin{array}{l}\text { Working } \\
\text { fluid }\end{array}$} & Material & Ethanol & & I.D & $8 \mathrm{~mm}$ \\
\hline & Volume & $1250 \mathrm{cc}$ & & Length & $8 m$ \\
\hline
\end{tabular}

\subsection{Experimental setup and condition}

Two aluminum heater blocks were attached to the evaporator to simulate instrument mass and eight cartridge heaters were inserted into them to provide heat loads to the evaporator. The cartridge heaters were connected to a DC power supply (N6702A). During the test, the entire LLHP was covered with ethylene propylene synthetic rubber as the thermal insulators. Temperatures were measured by $59 \mathrm{~T}$-type thermocouples. The data were collected using a data logger (Agilent 34970A). Red points in Fig. 3 denote the measurement locations. Four thermocouples were attached to the evaporator, eight to the $\mathrm{CC}$ and the additional $\mathrm{CC}$, twenty four to the condenser, six to the fin, and two to the heater blocks. The temperatures of the vapor and liquid lines were 
measured at six points each at intervals of two meters on the pipes, and six points on the insulator of the vapor line were also measured, and the temperature of ambient air was also measured. During the test, the ambient temperature was maintained at $24 \pm 1{ }^{\circ} \mathrm{C}$.

Experiments were conducted at the heat load increments of $40 \mathrm{~W}$ starting from $40 \mathrm{~W}$. Four experimental conditions were conducted, one was horizontal and the others were anti-gravity conditions. Under the antigravity conditions, evaporator was placed $30,60,100 \mathrm{~cm}$ higher than condenser respectively. Experiments were stopped when the average evaporator case temperature reached at $100{ }^{\circ} \mathrm{C}$ or the wick reached capillary limit.

\section{Experimental results and discussions}

\subsection{Experimental results}

The steady-state temperatures at the evaporator and the $\mathrm{CC}$ are shown by the solid lines in Fig. 4(a). The dotted lines in Fig. 4(a) are discussed in the following section. Fig. 4(b) showed the thermal resistance between the evaporator and the condenser that is defined by the equation (13) using the average temperatures.

$$
R=\frac{\bar{T}_{e c}-\bar{T}_{\text {con }}}{Q_{\text {load }}}
$$

The maximum heat load was $340 \mathrm{~W}$ and the thermal resistance was $0.12 \mathrm{~K} / \mathrm{W}$ at the maximum heat load under the horizontal condition. On the other hand, the maximum heat loads were $310,270,220 \mathrm{~W}$ and the thermal resistances were $0.15,0.17,0.22 \mathrm{~K} / \mathrm{W}$ at the $30,60,100 \mathrm{~cm}$ anti-gravity condition respectively. The uncertainty analysis of thermal resistance was conducted based on a root-sum-square method [15] and resulted in 3.3-4.1\% uncertainty. The evaporator temperature became higher as the evaporator was placed higher. This trend has been mentioned $[2,8,9,10]$. At high heat loads, however, the temperature difference became greater as anti-gravity effect increased, and this trend was incompatible with the previous study by Chuang [9]. This is because of an occurrence of the vapor layer in the outer surface of the wick and this is discussed in detail in section4.4.

\subsection{Estimation of the heat transfer coefficient}

The amount of heat loss from the vapor/liquid lines and the heat dissipation from the condenser were calculated by equation (14).

$$
Q_{x}=h_{x} A_{x} \sum_{l}\left(\left(T_{x}(l)+T_{x}(l+1)\right) / 2-T_{\text {amb }}\right)
$$

Where, the subscript $x$ indicates the each part of the LLHP i.e. vapor line $(v l)$, liquid line $(l l)$ and condenser (con). The heat loss from the evaporator and CC was estimated by equation (15) derived from the energy equation of entire part of the LLHP.

$$
Q l_{e v_{-} a m b}=Q_{\text {load }}-Q l_{v l_{\_} a m b}-Q l_{l_{-} a m b}-Q l_{c o n \_a m b}
$$

The heat transfer coefficients of vapor line and condenser were estimated by the equation (16) and (17) respectively.

$$
\begin{aligned}
& \frac{1}{h_{v l} A_{v l}}=C R_{v l}+\frac{\log \left(D_{i n s_{-} o} / D_{i n s_{-} i}\right)}{2 \pi k_{i n s}}+\frac{1}{\pi D_{i n s_{-} o} h_{a m b}} \\
& \frac{1}{h_{c o n} A_{c o n}}=R_{f i n}+\frac{1}{\left(A_{0}+\eta A_{f i n}\right) h_{f i n}}
\end{aligned}
$$

Equation (16) assumes the temperatures of inner and outer walls of the pipe are isothermal. Table 2 shows the estimation results of heat transfer coefficient. Where, the heat transfer coefficient at the vapor line is applied to the liquid line because of the same adiabatic condition. The uncertainty analysis showed that the heat transfer coefficient at vapor (liquid) line and condenser line have 7.9, and 10.7\% uncertainty respectively.

Table 2 Heat transfer coefficient

\begin{tabular}{|c|c|}
\hline & {$\left[\mathrm{W} / \mathrm{m}^{2} \mathrm{~K}\right]$} \\
\hline Vapor(Liquid) line & 1.79 \\
\hline Condenser line & 26.21 \\
\hline
\end{tabular}




\subsection{Estimation result of the amount of heat loss and dissipation}

Fig. 6 shows the calculation results of the amount of heat loss and dissipation as the function of the applied heat load. It is not shown in Fig. 6, however, heat was absorbed at the liquid line in some experimental conditions. As shown in Fig. 6(b), $71.4 \%$ of the maximum heat load was dissipated at the condenser under the horizontal condition. On the other hand, $62.8,61.8,57.1 \%$ of the maximum heat load was dissipated at the condenser under anti-gravity condition respectively. Comparison between the horizontal and anti-gravity condition showed the heat transfer efficiency under anti-gravity condition was lower than the horizontal condition. There are two possible reasons for this. Firstly as shown in Fig. 4(a), the evaporator temperature under anti-gravity conditions became higher than the horizontal condition. Consequently, heat leak from the evaporator to the $\mathrm{CC}$ was increased. Second reason is temperature dependence of the latent heat value. The value of latent heat of ethanol becomes lower as the temperature increases and as a result, the latent heat of vaporization decreased under anti-gravity condition.

\subsection{Comparison with computational model}

From the comparison between the experimental and the calculation result under the horizontal condition, $h_{e v}$, that is the heat transfer coefficient from the evaporator case to the outer surface of the wick is decided as 1800 $\mathrm{W} / \mathrm{m}^{2} \mathrm{~K}$. However, the number would decreases when the vapor layer occurs in the outer surface of the wick. This is called vapor blanket in [16,17]. Previous studies revealed that when evaporator is not coupled to the rest of the loop, the vapor blanket occurs at high heat load and the depth increases along with the heat load [16-19]. However, occurrence of the vapor blanket during anti-gravity operation has never been analyzed and this is essential for use in terrestrial field. As this model assumes the wick is fully saturated with the liquid, the heat transfer coefficient needs to be decided based on the test results when the vapor blanket appears.

The reason of the occurrence of the vapor pocket is the occurrence of nucleate boiling [20,21]. The degree of superheating of the outer surface was computed by eq. (18).

$$
\Delta T_{\text {sup }}=T_{e c}-T_{\text {sat }}
$$

This model assumed that the vapor pocket occurred when the eq. (18) exceeded the eq. (19) that is the degree of superheating for the occurrence of the nucleate boiling.

$$
\Delta T_{\text {nuc }}=\frac{2 \sigma T_{\text {sat }}}{\rho_{v} \lambda_{v} r_{\text {pore }}}
$$

The dotted lines in Fig. 4(a) shows the calculation results of the temperature of the evaporator case and CC. Fig.7 shows the calculation results of the degree of superheating expressed by eq. (18) and eq. (19) under the horizontal and 30,60,100 cm anti-gravity conditions. Here, the superheat values could be evaluated higher than actual values because the model does not consider the temperature difference between the core and the CC and define $T_{c c}$. And as a result, evaporation temperature $T_{e v}$ is evaluated lower than actual one. The results in Fig. 7 show several indications. First, under the horizontal condition, vapor pocket does not occur. On the other hand, nuclear boiling occurs when $280,220,180 \mathrm{~W}$ heat load under $30,60,100 \mathrm{~cm}$ anti-gravity conditions respectively. Therefore, the vapor pocket occurs easily as anti-gravity effect increased. The calculation results in Fig. 4(a) were in good agreement with the test results. Table 3 shows the adjusted numbers of the heat transfer coefficient. Here, this method does not directly consider a vapor blanket in the calculation model, but this is still valid because the heat transfer coefficient $\left(h_{e v}\right)$ is the only factor to fit the results. The adjusted results indicated that the thickness of the vapor pocket became deeper as anti-gravity effect increased.

Table 3 Heat transfer coefficient between the evaporator case and the wick

\begin{tabular}{|c|c|c|c|c|c|c|c|c|c|c|c|c|}
\hline$\left[\mathrm{W} / \mathrm{m}^{2} \mathrm{~K}\right]$ & $40[\mathrm{~W}]$ & $\cdots$ & $180[\mathrm{~W}]$ & $200[\mathrm{~W}]$ & $220[\mathrm{~W}]$ & $240[\mathrm{~W}]$ & $260[\mathrm{~W}]$ & $280[\mathrm{~W}]$ & $300[\mathrm{~W}]$ & $320[\mathrm{~W}]$ & $340[\mathrm{~W}]$ & $360[\mathrm{~W}]$ \\
\hline $0[\mathrm{~cm}]$ & 1800 & $\cdots$ & 1800 & 1800 & 1800 & 1800 & 1800 & 1800 & 1800 & 1800 & 1800 & 1800 \\
\hline $30[\mathrm{~cm}]$ & 1800 & $\cdots$ & 1800 & 1800 & 1800 & 1800 & 1800 & 1750 & 1680 & 1620 & - & - \\
\hline $60[\mathrm{~cm}]$ & 1800 & $\cdots$ & 1800 & 1800 & 1750 & 1680 & 1580 & 1520 & - & - & - & - \\
\hline $100[\mathrm{~cm}]$ & 1800 & $\cdots$ & 1700 & 1600 & 1500 & 1400 & - & - & - & - & - & - \\
\hline
\end{tabular}




\subsection{Calculation results of pressure losses over LLHP}

Fig. 8 shows the calculated distributions of the pressure losses for the LLHP. This result shows that the pressure losses from the vapor line and the wick are the dominant part of the LLHP. Anti-gravity effect is also critical for the total pressure losses. It is estimated that the operating limits are 340 and $300 \mathrm{~W}$ under 60 and $100 \mathrm{~cm}$ anti-gravity conditions respectively as the total pressure loss exceeds the bubble point pressure (18200Pa).

\section{CONCLUSIONS}

This research presented the design and the test results of the $10 \mathrm{~m}$ long distance loop heat pipe under horizontal and anti-gravity conditions. The important aspects of this research are summarized as follows:

i. The constructed LLHP could transport $340 \mathrm{~W}$ under horizontal condition. Furthermore, the test results under 30,60, $100 \mathrm{~cm}$ anti-gravity conditions showed the maximum heat transports were 310, 270, 220 $\mathrm{W}$ respectively.

ii. Evaluation of heat loss and dissipation from the each part of the LLHP showed that anti-gravity effect

iii. The numerical model showed good agreement with the experimental results by adjusting the heat transfer coefficient between the evaporator case and wick and this indicated the occurrence of vapor pocket.

\section{ACKNOWLEDGMENT}

This research was partly supported by JST, PRESTO.

\section{REFERENCES}

[1] Y. F. Maydanik, "Loop heat pipes," Applied Thermal Engineering, 25, pp. 635-657, (2005).

[2] J. Ku, "Operating Characteristics of Loop Heat Pipes," Proc. of 29th Int. Conf. on Environmental System, SAE Paper No. 1999-01-2007.

[3] S. Launay, V. Sartre, J. Bonjour, "Parametric analysis of loop heat pipe operation: a literature review," Int. J. Thermal Sciences, 46 (2007) 621-636.

[4] L. Lachassagne, V. Ayel, C. Romestant, Y. Bertin, "Experimental study of capillary pumped loop for integrated power in gravity field," Applied Thermal Engineering 35 (2012) 166-176.

[5] V.G. Pastukhov, Y.F. Maydanik, "Low-noise cooling system for PC on the base of loop heat pipes," Applied Thermal Engineering 27 (2007) 894-901.

[6] L. Vasiliev, D. Lossouarn, C. Romestant, A. Alexandre, et al., "Loop heat pipes for cooling of high-power electronic components," Int. J. Heat and Mass Transfer 53 (2009) 301-308.

[7] M. Mitomi, H. Nagano, "Long-distance loop heat pipe for effective utilization of energy,” Int. J. Heat and Mass Transf., 77, pp. 777-784, (2014).

[8] R. R. Riehl, "Comparing the behavior of a loop heat pipe with different elevations of the capillary evaporator," International Conference On Environmental Systems, Colorado Springs, July 2004 (SAE paper 2004-01-2510).

[9] P.-Y.A. Chuang, "An improved steady-state model of loop heat pipes based on experimental and theoretical analyses," PhD thesis, The Pennsylvania State University, 2003, 271 pp.

[10] D.C. Mo, N. Ding, S.S. Lu, "Gravity Effects on the Performance of a Flat Loop Heat Pipe,” Microgravity Sci. Technol (2009) 21 (Suppl 1):S95-S102. 
[11] Y. Tang, R. Zhou, L. Lu, Z. Xie, "Anti-Gravity Loop-shaped heat pipe with graded pore-size wick," Applied Thermal Engineering, 36 (2012) 78-86.

[12] NIST Reference Fluid Thermodynamic and Transport Properties Database (REFPROP): Version 9.1 NIST Standard Reference Database 23, 2013. <http://www.nist.gov/srd/nist23.cfm>

[13] H. Nagano, F. Fukuyoshi, H. Ogawa, "Development of an experimental small loop heat pipe with polytetrafluoroethylene wicks". J. Thermophys. Heat Transfer 25 (4) (2011) 547-552.

[14] S.C. Wu, T.W. Gu, D. Wang, Y.M. Chen, Study of PTFE wick structure applied to loop heat pipe, Applied Thermal Engineering, 81 (2015) 51-57.

[15] R.J. Moffat, "Describing the uncertainties in experimental results," Exp. Therma. Fluid Sci. 1 (1) (1988) 3-17.

[16] T.S. Zhao, Q. Liao, "On capillary-driven flow and phase-change heat transfer in a porous structure heated bu a finned surface: measurement and modeling". Int. J. Heat and Mass Transfer, 43, 2000, pp. 1141-1155.

[17] D. Khrustalev, A. Faghri, "Heat transfer in the inverted meniscus type evaporator at high heat fluxes," Int. J. Heat Mass Transfer, 38 (16) (1996) pp. 3091-3101.

[18] R. Boubaker, V. Platel, A. Berges, M. Bancelin, E. Hannezo, "Dynamic model of the heat and mass transfer in an unsaturated porous wick of capillary pumped loop," Applied Thermal Engineering, 76 (2015) 1-8.

[19] L. Mottet, T. Coquard, M. Prat, "Three dimensional liquid and vapour distribution in the wick of capillary evaporators," Int. J. Heat and Mass Transfer, 89 (2015) 636-651.

[20] T. Kaya, J. Goldak, "Numerical analysis of heat and mass transfer in the capillary structure of a loop heat pipe," Int. J. Heat and Mass Transfer, 49 (2006) 3211-3220.

[21] M. Nishikawara, H. Nagano, L. Mottet, M. Prat, "Formation of unsaturated regions in the porous wick of a capillary evaporator,” Int. J. Heat and Mass Transfer, 89 (2015) 588-595.

Figure captions

Fig. 1 LHP configuration

26 Fig. 2 Solution flowchart for the LHP model

Fig. 3 Overview figure of the LLHP and the measurement position of the temperature

Fig. 4 Effect of heat load on (a) evaporator case and CC temperatures (b) thermal resistance

Fig. 6 Heat load and gravity effects on heat loss and dissipation of each experimental condition

30 (a) Amount in each heat load

(b) Ratio in each maximum heat load

Fig. 7 Calculation result of the degree of superheating under (a) $0 \mathrm{~cm}$ (b) $30 \mathrm{~cm}$ (c) $60 \mathrm{~cm}$ (d) $100 \mathrm{~cm}$ antigravity condition

Fig. 8 Calculation results of the pressure loss over the parts of the LLHP 


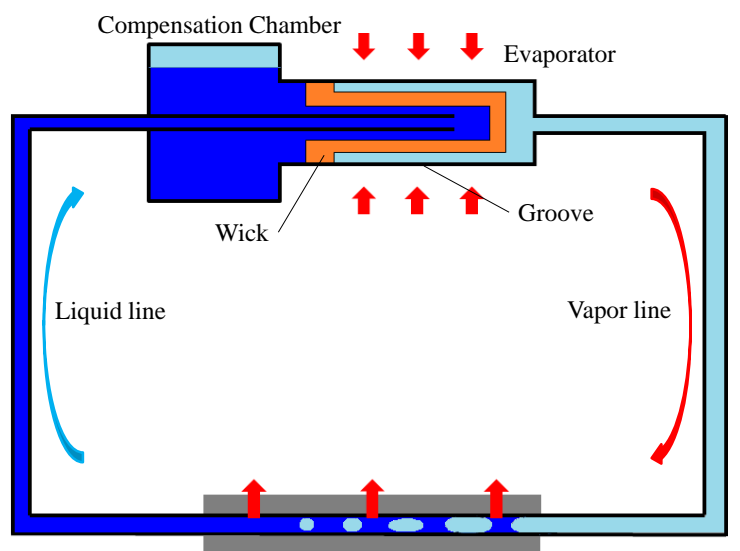

Condenser

Fig. 1 LHP configuration

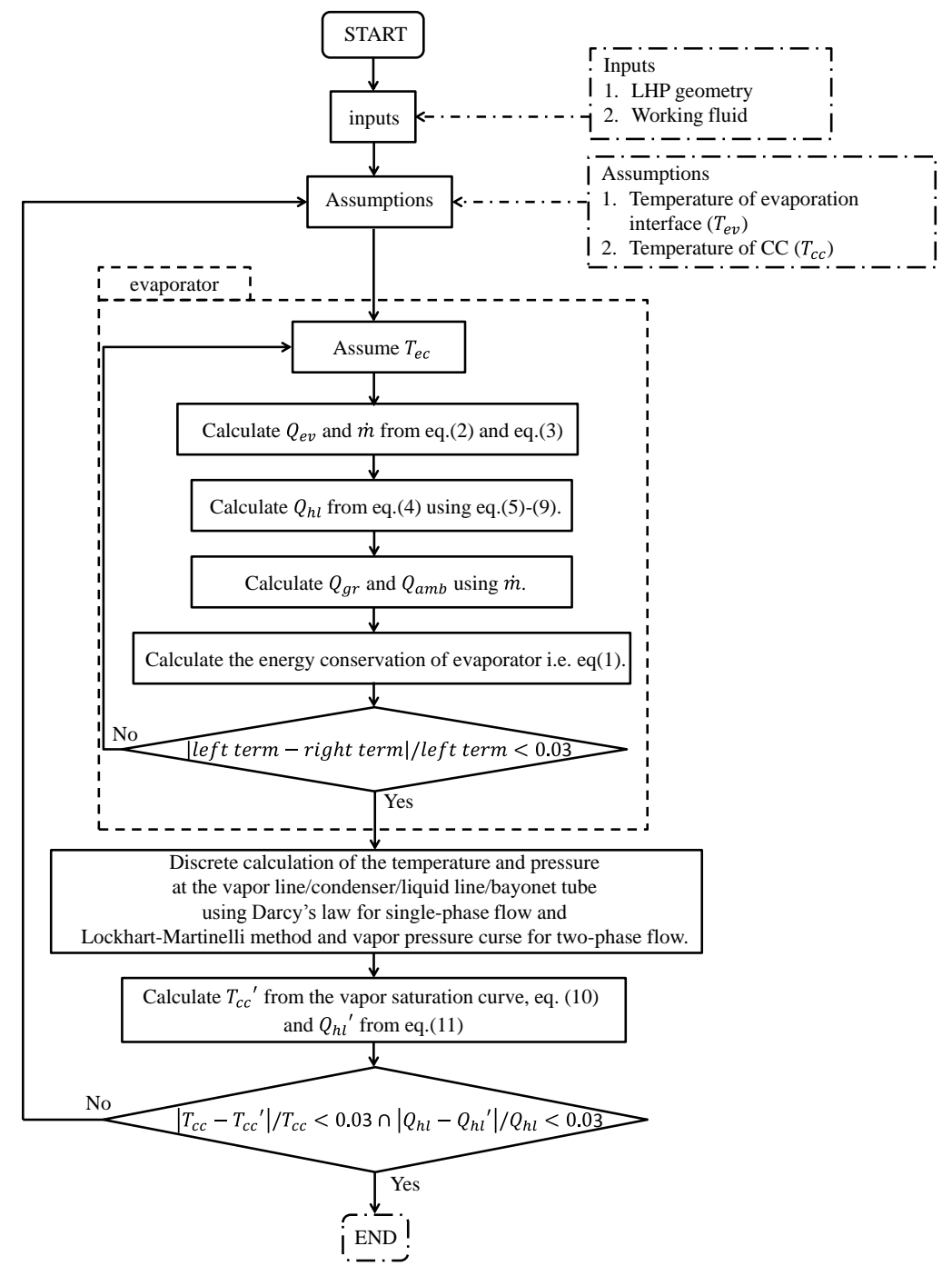

Fig. 2 Solution flowchart for the LHP model 


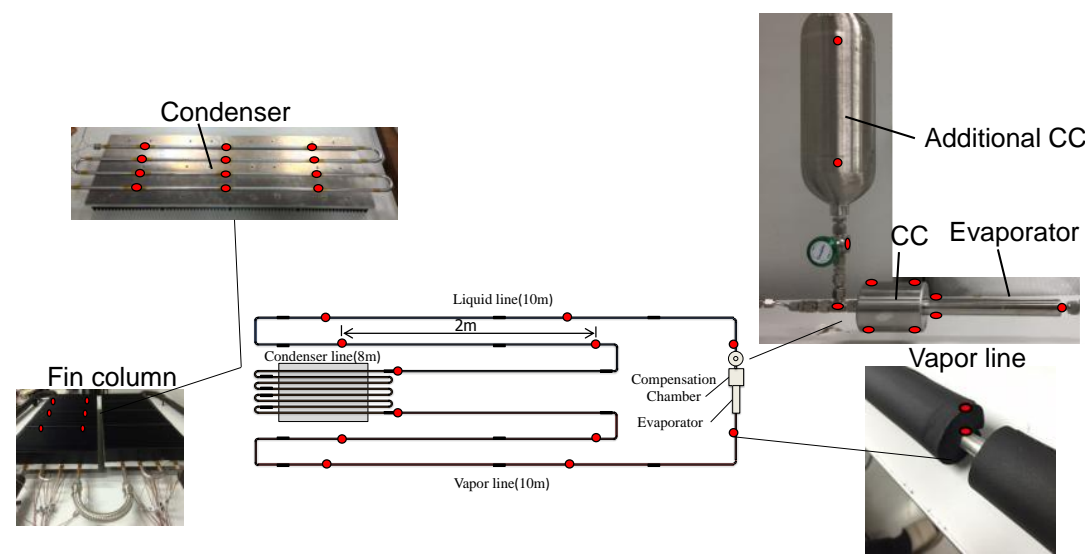

Fig. 3 Overview figure of the LLHP and the measurement position of the temperature

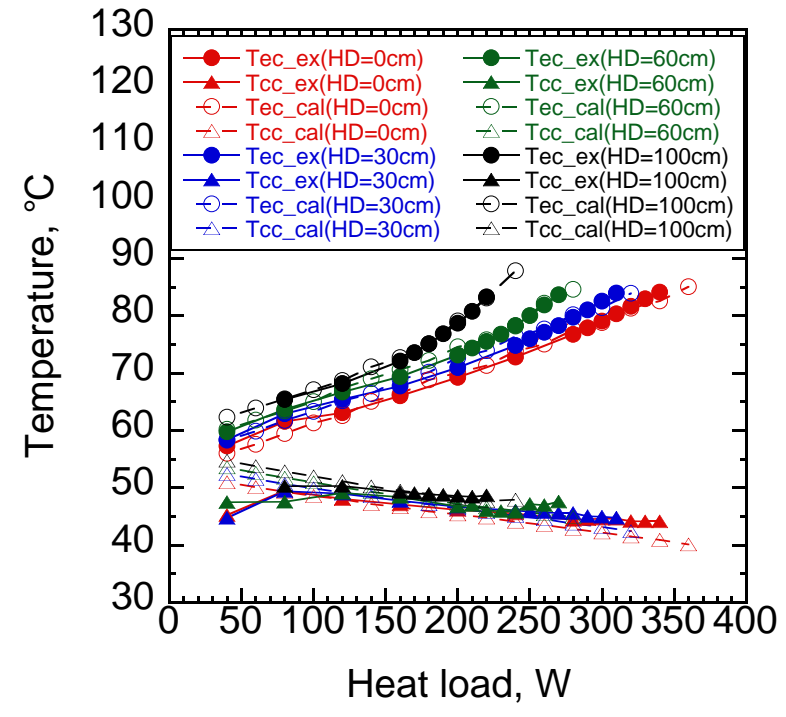

(a)

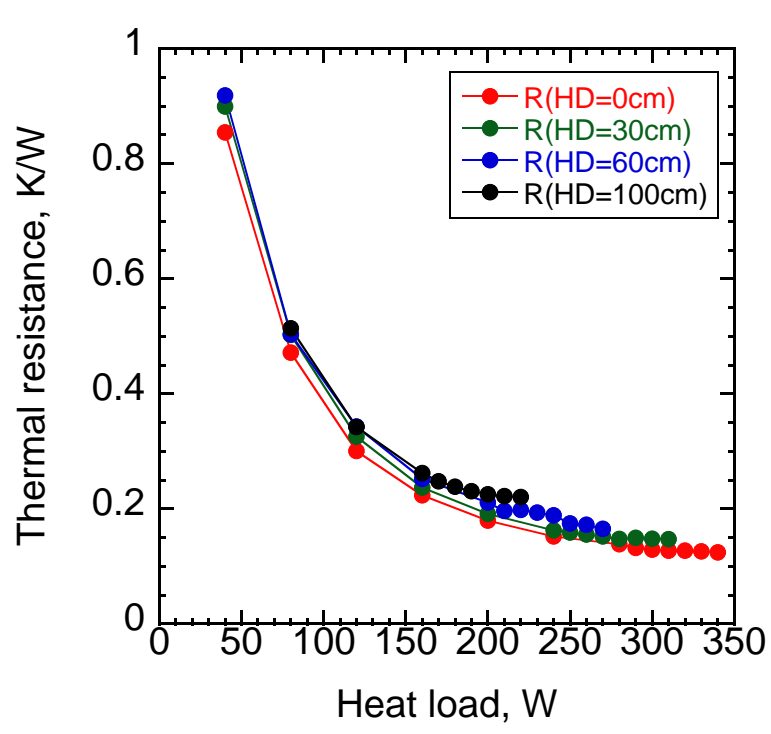

(b)

Fig. 4 Effect of heat load on (a) evaporator case and CC temperatures (b) thermal resistance
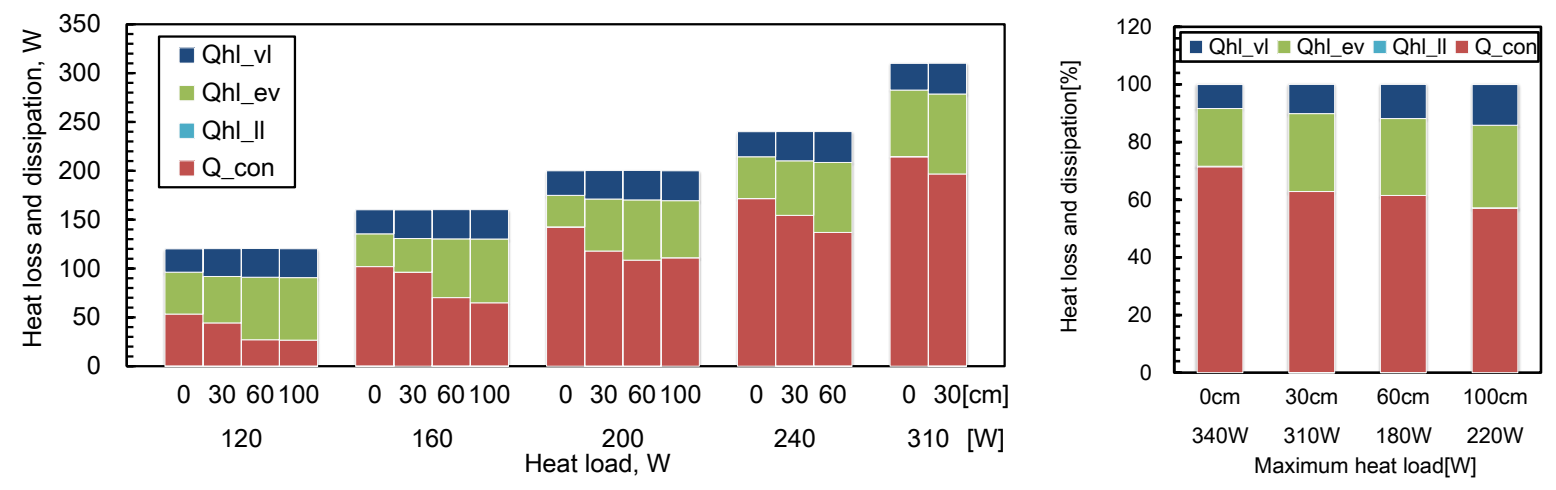

(a) Amount in each heat load

(b) Ratio in each maximum heat load

Fig. 6 Heat load and gravity effects on heat loss and dissipation of each experimental condition 


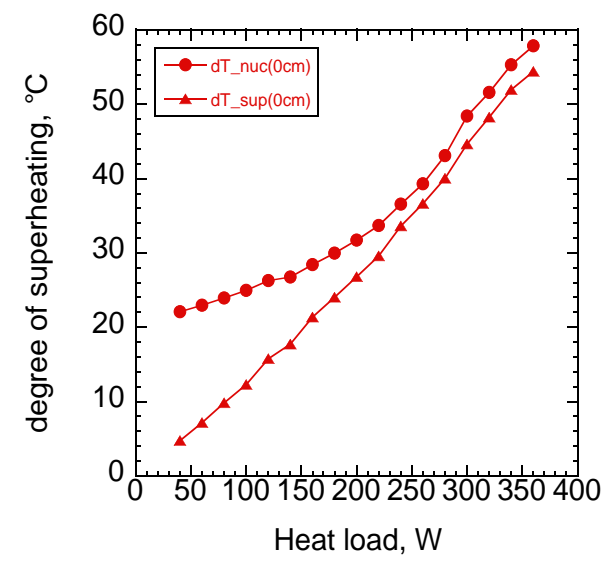

(a)

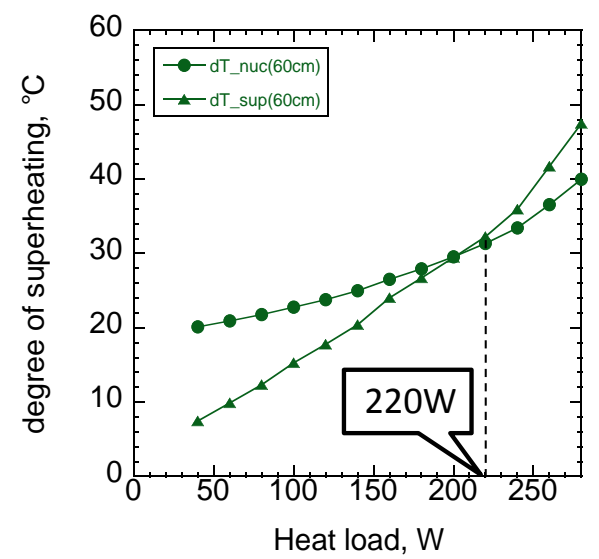

(c)

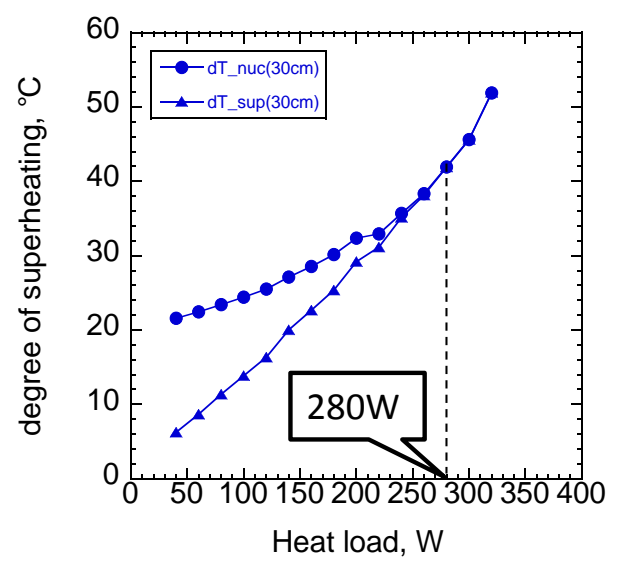

(b)

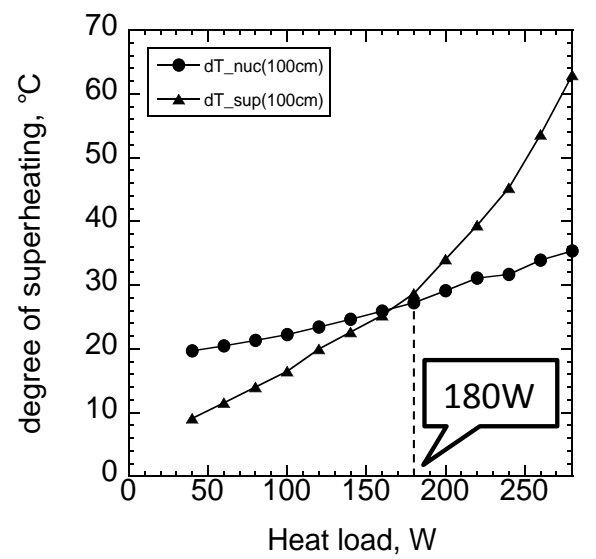

(d)

Fig. 7 Calculation result of the degree of superheating under (a) $0 \mathrm{~cm}$ (b) $30 \mathrm{~cm}$ (c) $60 \mathrm{~cm}$ (d) $100 \mathrm{~cm}$ anti-gravity condition

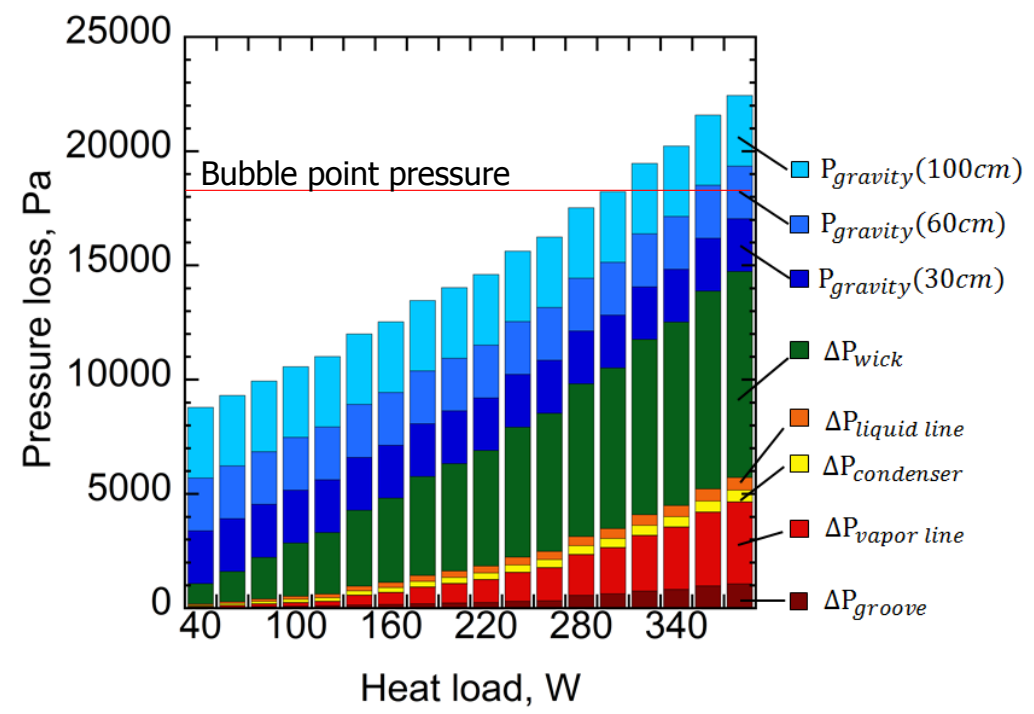

Fig. 8 Calculation results of the pressure loss over the parts of the LLHP 